\title{
SCALING-UP PARTICIPATION AT USAID
}

Faith Corneille, MA-IR, MPA

The Maxwell School of Syracuse University

Syracuse, NY 13244-1090 USA

e-mail: faithcorneille@yahoo.com

phone: 315-372-8605

Jeremy Shiffman, Ph.D.*

Assistant Professor of Public Administration

The Maxwell School of Syracuse University

Syracuse, NY 13244-1090 USA

e-mail: jrshiffm@maxwell.syr.edu

phone: 315-443-4928; fax: 315-443-9734

October 8, 2003

Forthcoming in Public Administration and Development

*Corresponding author 


\section{Summary}

Since the 1970s many non-governmental development organizations have moved away from top-down modes of operation toward participatory practices that hand over decision-making power to the poor. The bilateral development agencies of the industrialized states have been slower to follow suit, but in the 1980s and 1990s a number also initiated participatory-oriented reforms.

Development scholars have paid little attention to reforms of the larger organizations. In this paper we analyze the efforts of the United States Agency for International Development to embrace participation in the 1990s. Internal reformers managed to change some agency procedures but had only limited success in institutionalizing participatory practices. Forces internal to the agency, including rigid rules and employee incentive structures hampered reform efforts. Also, while some developments external to the agency facilitated participation, many others, including legislative interference and shifting national policy priorities, hindered change toward participation. The case reveals how complex webs of accountability relationships make participatory-oriented transformation a cumbersome process in large development organizations. Change toward participation can succeed, but only if reformers acknowledge and consider existing institutional constraints. 


\section{Introduction}

In the past decade a number of large development organizations have made efforts to hand over greater project decision-making authority to local people in developing countries. They have been influenced by a new development paradigm known as participation that rejects top-down modes of operation in favor of practices that recognize the agency and expertise of the poor.

The paradigm emerged in the 1970s, shaped by the ideas of Brazilian educationalist Paolo Freire who argued that development must concern the empowerment and liberation of people in disadvantaged circumstances (Freire, 1968; Long, 2001). Hundreds of non-governmental organizations rapidly embraced the philosophy, realizing that local people had extensive knowledge about the problems they faced, considerable capacity to identify solutions to these problems, and the ability to select, design and carry out projects more relevant to and effective in addressing their needs than those devised by external experts.

Not until the mid 1980s did the bilateral development agencies of the industrialized states begin experimenting with these practices. They were slow to do so because participatory modes of operation did not fit in well with their organizational cultures. Policy was made at the top and subordinates expected to follow directives; operating procedures were rigid and rule-driven; well-educated individuals accustomed to dispensing advice dominated the organizations. None of these features were compatible with the philosophy that priorities should emerge from below, procedures should be flexible and the poor should be recognized as the true experts on matters concerning their own livelihoods. 
Top-down practices still predominate in most large bilateral development agencies. Within many, however, reformers have made attempts to scale-up participatory practices. With only a few exceptions (Blackburn, 1998; Long, 2001; Bainbridge et al., 2000), development scholars have given little notice to these reforms. They deserve greater attention since the experiences of individual agencies may provide lessons for other organizations, and since these changes may have considerable influence on the future of development practice.

It is with these considerations in mind that we analyze the attempt of the United States Agency for International Development (USAID) to scale-up participation in the 1990s. Situated inside the world's largest federal bureaucracy and within a vibrant democracy, and holding a central place in the global development community, the agency presents an interesting case since it is particularly susceptible to the influence of external actors and to the constraints of internal regulations, making reform an especially complex process. The case offers a window into the difficulties large development organizations face in scaling-up participation.

We used a process-tracing methodology to construct the case history, employing multiple sources of information to cross-check historical details and to detect causal patterns. We conducted unstructured in-depth interviews with USAID and NGO officials, consulted numerous internal agency documents, analyzed U.S. government reports and drew on published scholarship. Also, we asked a former USAID official to review the manuscript for factual accuracy.

In the following section we draw from development scholarship to identify factors that have influenced the behavior of large development organizations. We then present an account of the reform initiative. In the analysis and concluding sections we identify facilitating and constraining factors, lessons learned and areas for future consideration on the scaling-up of participation in large development organizations. 


\section{Background}

Bilateral development agencies operate with constricted autonomy (Lancaster, 1999). External forces including political pressures in home countries, demands from recipient nations and global norms on foreign aid shape and circumscribe their behavior. Also, agencies are constrained by internal procedures. Reforming their practices therefore can be complex and time-consuming.

Domestic political pressures shape agency behavior in several ways. National leaders use agencies for foreign policy objectives, diverting them from strictly development-oriented missions (Hook, 1995; Lancaster, 1999). The French government traditionally has offered assistance to sustain a sphere of influence among former colonies in Africa, pursue great power ambitions and preserve French language and culture (Hook, 1995; Lancaster, 1999). Much Japanese aid is geared toward advancing the country's commercial interests. The United States used aid during the Cold War to cultivate allies in its ideological battles with the Soviet Union, and gives a sizable portion of present assistance to Israel and Egypt to ensure their commitment to the Camp David peace accords. Also, domestic political agendas push agencies in unintended directions. The Italian public revolted against funding development when political interests captured the aid bureaucracies (Lancaster, 1999). Constantly shifting congressional demands force USAID leaders to re-orient priorities (Hook, 1995; Rondinelli, 1989).

On the other hand, some agencies have carved out substantial autonomy and maintained a focus on development-oriented objectives (Lancaster, 1999). The Swedish International Development Agency is semi-independent of the Ministry of Foreign Affairs, governed by its own board of directors, the beneficiary of widespread public support for development assistance and not burdened by a state involved in great power politics. The United Kingdom's Department for International Development (DfID) has operated since 1997 as an independent ministry, is relatively free from parliamentary 
interference and has enjoyed the support of many domestic NGOs, building a reputation as one of the most effective development agencies in the industrialized world.

Recipient country environments also shape and constrain behavior, as agencies face shifting political circumstances and cultural complexities not always conducive to agency autonomy. In Nigeria, for instance, local elders sought to install their own representatives rather than those favored by the community in a DfID project that aimed to promote local participation in health (Unom, 2000). In the same project DfID was forced to work with a para-statal rather than the Ministry of Health, as European Community regulations prevented the United Kingdom from engaging a new military government. In Egypt, agencies in the bureaucracy used delay tactics in an attempt to subvert a USAID housing project (Taher, 2001). In Nepal international donors were unable to bridge cultural gaps with domestic health officials and villagers, resulting in the creation of unworkable plans and leading to the failure of a national program for community participation in healthcare (Justice, 1989). By contrast, a 1994 change in the Bolivian constitution acknowledging a multiethnic society and calling for the inclusion of indigenous groups in the political process has facilitated participatory development in that country (Anderson, 1999).

Global norms also influence the practices of development agencies. Since the end of the Cold War many agencies have advanced a shared agenda to encourage recipient countries to liberalize their economies and democratize their political systems (Grant and Nijman, 1998). The Development Assistance Committee (DAC) of the Organization for Economic Cooperation and Development, a grouping of the world's industrialized states, has drafted guidelines urging states to adopt participatory practices (OECD, 1994) and to give at least $0.7 \%$ of their GNP for development purposes. Such publicly-endorsed statements place pressure on member states to conform to agreed upon principles. 
Agencies face constraints not only from forces external to themselves but also from forces within. Internal cultures encourage inertia and risk-averse behavior (Thompson, 1998; Cracknell, 2001). Rules on procurement and reporting and concerns about recipient accountability constrain flexibility and discourage the handing over of decision-making authority. Also, advocates have emphasized that participation is as much about personal change as it is about institutional transformation (Chambers, 1997; Edwards and Sen, 2000), and reformers face the considerable challenge of altering the mindsets of agency employees cognizant of their own expertise but unaccustomed to acknowledging its presence in local peoples. On the other hand, given sufficient commitment and careful strategizing political entrepreneurs have managed to reform agency cultures (Blackburn, 1998; Wilson, 1989). Also, performance assessment frameworks have been created for large development organizations that facilitate the institutionalization of aid-giving practices that consider the needs of the poor (Saltmarshe et al., 2003).

The bilateral development agencies of industrialized states, then, do not operate in vacuums but rather within multiple environments that shape and constrict possibilities for change and action. In the section that follows, we consider these influences as we examine USAID efforts to scale-up participation.

\section{The Case}

\section{Reform origins}

For several decades USAID had promoted democratic governance and encouraged employees to consult local people in project development, but it was not until the 1990s that a reform initiative grounded in the participation paradigm emerged inside the agency. A number of factors shaped its appearance. 
In the 1980s, the global spread of participatory norms began to reach the bilateral development agencies (Long, 2001). The Swedish and Germans were the first to begin experimenting with participation. In 1990 the World Bank brought together multiple agencies, including USAID, in a participation learning group. Around the same time the United States Congress approved the Development Fund for Africa (DFA) that mandated that USAID consider local perspectives and consult with the rural and urban poor in subSaharan Africa. Influenced by NGOs, other bilateral agencies, World Bank initiatives, and congressional legislation, USAID officials began to pay greater attention to these ideas.

In the early 1990s the agency faced a series of challenges to its mission and survival that reinforced an impetus toward reform. The end of the Cold War necessitated a reconsideration of an aid regimen grounded in ideological struggle against communism. The agency also came under attack from several congressional leaders who advocated its absorption into the State Department, and from a congressional task force that called for its complete abolishment (Gore, 1993). President Clinton defended USAID but Congress cut back its resources leading to the closing of 24 field missions in the 1990s (USAID, 1996).

In January 1993 the Clinton Administration called for a government reform initiative that came to be known as the National Performance Review (NPR). Vice President Gore led an effort to bring standards of private sector accountability to federal agencies to make them more efficient, entrepreneurial and client-focused. Public agencies were obligated to define program objectives, create annual performance plans specifying measurable goals and publish reports showing results. The NPR's report on USAID was highly critical, noting that the agency had no clear mission and burdensome operating procedures, and lacked a customer orientation (Gore, 1993). The report called for the agency's immediate reform. 
Shortly thereafter, responding to the NPR initiative, new agency administrator J. Brian Atwood offered USAID as a laboratory for re-engineering in a major attempt to overhaul agency procedures and gain credibility for USAID. In a separate but less encompassing initiative, Atwood launched an effort to strengthen the commitment of the agency to participation, appointing Diane La Voy to head it. The final NPR report on USAID published in late 1993 stated that participation was critical for project success and that the agency should create incentives for the inclusion of the poor in all phases of the project management cycle.

\section{Reform implementation}

Atwood released a statement in November 1993 that marked the official launch of a participation initiative inside the agency (Atwood, 1993). Reflecting the language of NPR reform and of the participatory paradigm, the agency identified its primary stakeholders to be, "the people of developing and transitional countries who are end-users or beneficiaries of USAID programs, typically poor people” (La Voy and Charles, 1998).

La Voy embarked on a series of activities to promote the concept of participation among agency employees and to distribute information about participatory work already taking place. She organized a series of seminars for staff to discuss the benefits and challenges of participatory approaches, inviting USAID, World Bank, NGO and other officials to present at 23 sessions from 1994 to 1997 (USAID, 1994-1997). Electronic summaries were distributed to approximately 900 individuals from USAID and implementing NGOs, an association that came to be called the 'participation network.' To advise the effort she created a participation working group. She had a set of eleven case studies on participatory practices produced and made available electronically (USAID, n.d.). Also, she organized workshops at USAID headquarters on participatory 
techniques. These activities resulted in the sharing and diffusion of participatory ideas and practices among hundreds of agency employees and implementing partners.

For the NPR-mandated reforms USAID leaders drew heavily from private sector techniques to re-orient management practices throughout the agency. They asked units to develop customer service plans, to consult customers in their creation and to manage for results (La Voy and Charles, 1998). Strategic objectives that facilitated flexibility in action and consultation in the development of project aims replaced planned activities and projects. A new automated system for internal regulations was created to replace 33 handbooks containing 700 chapters, 12,000 pages of text and 2,000 forms (USAID, 1996). Ten USAID missions were designated 'country experimental labs,' to apply and report on new management practices (USAID, 1996). As a result of these reforms agency procedures were streamlined in ways that gave local USAID representatives potentially greater flexibility to design programs that included and considered the interests of the poor.

From 1994 to 1996 USAID enjoyed a relatively cooperative relationship with a Democratic Congress. During this period USAID and NGO allies sought to re-write the 1966 Foreign Assistance Act which was the original legislative basis for aid (Haugaard, 1997). The legislation would have re-oriented budgeting processes, removed some earmarked funds and released the agency from many mandates that constrained the agency over the years. However, in 1996 the Republicans took Congress and killed the bill. Shortly thereafter, chair of the Senate Foreign Relations Committee Jesse Helms led a new attack on the agency, accusing it of inefficiency, mismanagement, waste, corruption and resistance to reform, and remarking that the American people were tired of pouring their hard-earned money down 'rat-holes' (Bering-Jensen, 1994). One result was that the efforts of agency leaders were again diverted toward defense of the 
organization, leaving them with less time to focus on other initiatives, including the promotion of management reforms that would have facilitated participatory approaches.

\section{Reform impact}

There is evidence that some agency projects prior to the 1990s had incorporated participatory practices. In the new decade, however, a considerable number of new programs introduced significant local consultation and inclusion of under-represented groups (USAID, 1994-1997). In Zambia officials interviewed mothers, female clinic patients and community leaders and involved local NGOs and universities in the design of a child health program. When a study revealed low community involvement in a decentralized water project in Nicaragua, USAID trained municipal officials in ways to increase participation, resulting in a campaign that brought about the involvement of students, teachers, community members and religious leaders. In Bolivia, USAID funded a forest preservation project of an Izoceño Guarani Indian NGO, designed and implemented by the group in consultation with indigenous communities. Past regulations would have precluded working with such a small organization due to complex grant and reporting requirements. After Malawians voted for a multiparty democratic system in 1993, USAID sponsored a project to bring women into the process, leading to their inclusion in political party delegations that drafted a national constitution. In Haiti, USAID gave extensive flexibility to a grantee, the International Organization for Migration (IOM) in the administration of food programs. The IOM met with over 500 Haitians, included 130 local elected officials, and gave its 13 teams deployed throughout the country decision-making authority to spend up to $\$ 5,000$ on any project, each of which required citizen board or community group oversight. When the State Department decertified Nigeria for its failure to clamp down on drug-trafficking USAID was able to continue working with the government on a number of participatory development 
projects because financing came from the Development Fund for Africa, the Congressionally-approved program that mandated consultation of local people.

Political instability in recipient countries thwarted other USAID attempts at consultation and inclusion (USAID, 1994-1997). In Chad the agency developed a participation plan but a poor harvest and several coup d'etats blocked its implementation. In Togo after a dictator had been overthrown and the country was transitioning to democracy USAID helped organize national conferences to bring the poor into the political process, but their voices were drowned out by the interference of an old president and bureaucrats, and by the emergence of strikes and violence that closed government and NGO offices for extended periods. In Bosnia after the Dayton Peace Accords political authorities in Mostar and Sarajevo blocked USAID efforts to build local institutions for democratic participation. In Niger USAID funded a disaster mitigation project governed by local village management committees; however, agency sponsorship ended after a 1996 military coup and election fraud that obligated USAID to withdraw its mission from the country.

Obstacles internal to the agency also hampered reform efforts (La Voy, 1996). In 1997 the agency undertook an evaluation of the reforms (Baltimore et al., 1998), receiving over 600 responses from staff with follow-up input from approximately 300 USAID partners through focus groups, surveys and interviews. The evaluation revealed that while agency employees perceived some change in field missions they saw considerable inertia in the Washington headquarters, and confusion surrounding the reforms. For instance, many employees did not know how to use the revamped automated directives system that was supposed to clarify and simplify policies and procedures, and did not understand how to integrate strategic objectives into their operations. Also the evaluation indicated that institutional incentives continued to discourage consultation: agency employees were told to be participatory but received no 
extra resources to undertake these time and resource-intensive processes; they received few or no rewards for making the attempt at being inclusive; they continued to be pressed to meet short-term quantifiable targets that did not capture the value of participation; and they were caught between the imperatives of meeting the demands passed down to them from Washington and being responsive to customers. The evaluations indicated that change had occurred in piecemeal fashion and only in certain pockets in the agency.

Recent domestic and international political developments also have affected reform efforts. After fending off attacks from Congress for decades, USAID lost its bid to preserve autonomy from the State Department when in late 1998 President Clinton announced that the USAID Administrator would report to the Secretary of State. USAID remains an independent agency but this new relationship has diminished its freedom of action. Also, the September $11^{\text {th }}$ terrorist attacks and the appointment of a new administrator under a Republican president have moved other issues to the top of the USAID agenda, diminishing priority for participatory-oriented reforms (Barber, 2002).

\section{Analysis}

\section{Factors influencing the participation initiative}

In the 1990s reformers made a serious attempt to scale-up participation at USAID. Several factors contributed to the appearance of the initiative including: a global environment in favor of participation; the need for a new ideological imperative for foreign assistance with the end of the Cold War; congressional pro-participation legislation and demands for agency reform; a presidential administration interested in government efficiency and responsiveness; the agency’s involvement in these government reform efforts; and the selection of an administrator sympathetic to participation who perceived a window of opportunity for change. The agency head's 
commitment to the initiative and the organization of multiple internal forums for learning resulted in the widespread sharing of experiences, diffusion of knowledge and growth in support for the participatory paradigm inside the agency. Also, managerial reforms directed toward efficiency and decentralization of decision-making provided a supportive environment for the adoption of participatory practices. During the decade a number of USAID missions supported projects that handed over considerable decision-making power to the poor.

It is uncertain, however, the degree to which the initiative altered the agency's predominant modes of operation. Multiple forces internal and external to the agency hampered institutionalization of participatory practices. Internally, resource constraints, ongoing top-down directives from agency headquarters, rigid rules and procedures and the failure to substantially change reward structures meant that employees had few incentives to carry out extensive consultations with the poor. In particular, the complex procurement requirements that USAID was required to follow presented challenges to agency reform. Externally, congressional interference and earmarks, shifting national policy priorities, global crises and political instability in recipient countries distracted the agency from its pursuit of a participation agenda.

\section{Scaling-up participation in large development organizations}

The case reveals how the effort to scale-up participation at USAID was complicated by the agency's entanglement in a web of accountability relationships that constricted its capacity for independent action. USAID was not without autonomy; however, that autonomy was circumscribed. The case suggests that institutionalizing participation in large development organizations requires more than committed agency employees. It also requires supportive legislators who embrace the concept and are willing to appropriate financial resources toward the cause; national administrations that 
sustain participation as a policy priority even as new domestic and foreign policy issues arise; foreign ministries that view aid as something more than a tool of foreign policy; and the revamping of internal rules that provide little incentive for employees to consult the poor.

Past development scholarship is relevant for analyzing the possibilities of scalingup participation in large development organizations. These agencies are subject to multiple influences, including global ideologies, domestic political forces, recipient country conditions and their own bureaucratic cultures. Where conditions are favorable, such as in Sweden, other Scandinavian countries and the United Kingdom, reform toward participation may proceed more easily. Where conditions are less favorable, such as in the United States, Italy and France, reform may be cumbersome. In these environments reformers will need to be particularly strategic to advance the participation agenda. We offer three considerations concerning strategy development.

First, opposition should be anticipated and considered from the outset. Adopting participation is contentious since it requires a release of control, alters the distribution of power and necessitates fundamental shifts in practice. Reformers will confront resistance from legislators who seek to earmark funds for particular causes, a practice that often constrains the flexibility needed to sustain participation. They will face agency administrators who are accustomed to determining priorities and are reluctant to give up that authority. They will encounter mid-level officials who have spent decades acquiring expertise, are disinclined to check their inclinations to disperse that expertise, and are unconvinced that poor people have the requisite knowledge to understand their own needs and to select and carry out relevant projects. Because of these and other barriers, creating a policy environment favorable for participation is not a change that can happen overnight: it requires the cultivation of political allies, strategies to neutralize the 
opposition of groups that stand to lose power and sustained efforts to alter the beliefs of officials who do not understand the concept and benefits of meaningful participation.

Second, and related to this point, arguments for participation should be framed carefully. We share the view of those at the forefront of promoting the paradigm (Chambers, 1997; Blackburn, 1998): the principal reason to embrace participation concerns individual dignity - the Freirean moral imperative that the poor have the right, capacity and wisdom to decide for themselves on matters concerning their own livelihoods. A call for action made on these grounds alone, however, will not likely result in the transformation of long-standing bureaucratic practices. There is a need to position the issue in terms of other benefits that may be more appealing to senior administrators and policy-makers concerned with the management of large organizations and aid effectiveness. For instance, participation will lead to greater efficiency and project sustainability, as communities select programs that meet their own needs, come to own these programs and agree to contribute their own resources, thereby enabling agencies to pull out more rapidly without fear of project collapse, and to support many more projects than they could otherwise. Similarly, reformers will need to find effective ways to communicate results to policy-makers. Some participatory projects, effective over the long-term, may not be so in the short-term as considerable groundwork may be necessary to get them running. This situation creates difficulties for oversight agencies that require short-term quantifiable results in order to justify ongoing funding. Reformers need to find reporting mechanisms and benchmarks that can communicate annual progress, while at the same time targeting key officials in these agencies so they come to understand the longer-term time frames needed to achieve results in some participatory projects.

Third, careful consideration must be given to employee incentive structures. A recent article in this journal argues for the creation of performance evaluation 
frameworks for development agency officials that involve not only upward accountability to agency leaders but also downward accountability to the poor (Saltmarshe et al., 2003). This point is relevant to the issue of institutionalizing participation. In the case of USAID, few employees fundamentally changed their practices since they had little incentive to do so. Altering employee behavior involves more than a change of mindset. It also involves better compensation and promotions for those willing to take the risks of uncertain outcomes that participation entails.

\section{Conclusion}

In the 1990s USAID reformers made a determined effort to move the agency toward more participatory practices. They achieved limited results, largely because of constraints imposed by internal regulations and external demands. Although USAID reformers faced a particularly challenging situation, they were not unique in this regard: complex webs of accountability entangle all large development agencies. Under these conditions change toward participation can take place, but officials must consider carefully their agencies’ difficult institutional environments as they devise reform strategies. 


\section{References}

Anderson V. 1999. Popular Participation in Bolivia: Does the Law "Participación Popular" Secure Participación of the Rural Bolivian Population? Centre for Development Research, Institute for International Studies, CDR Working Paper 99.6. Retrieved June 2003 from CDR: http://www.cdr.dk/working_papers

Atwood J. 1993. Statement of Principles on Participatory Development. Retrieved November 2002, from USAID: http://www.usaid.gov

Bainbridge V, Foerster S, Pasteur K, Pimbert M, Pratt G, Arroyo IY. 2000. Transforming Bureaucracies: Institutionalising Participation and People Centred Processes in Natural Resource Management - an Annotated Bibliography; Russell Press: Nottingham, UK.

Baltimore L, Reyna L, Charles C, Haecker J, Harrison-Burns J, Schultz P. 1998. Stocktaking of Reforms in Agency Operations. Retrieved September 2002 from, USAID’s Development Clearinghouse, ID \# PD-ABQ-570: http://www.dec.org

Barber B. 2002. Andrew Natsios: getting USAID on its feet. Foreign Service Journal September issue: 20-27.

Bering-Jensen H. 1994. Foreign aid: from waste to investment. Insight on the News 10(5): 6-10.

Blackburn J (ed.). 1998. Who Changes? Institutionalizing Participation in Development; Intermediate Technology Publications: London.

Chambers R. 1997. Editorial: responsible well-being - a personal agenda for development. World Development 25(11): 1743-1754.

Cracknell BE. 2001. Knowing is all: or is it? Some reflections on why the acquisition of knowledge, focusing particularly on evaluation activities, does not always lead to action. Public Administration and Development 21(5): 371-379.

Edwards M, Sen G. 2000. NGOs, social change and the transformation of human relationships: a $21^{\text {st }}$ century civic agenda. Third World Quarterly 21(4): 605-616.

Freire P. 1968. Pedagogy of the Oppressed; The Seabury Press: New York.

Gore A. 1993. Creating a Government that Works Better and Costs Less. National Performance Review submitted to President Clinton. Retrieved January 2003 from University of North Texas Libraries, Government Documents Department:

http://govinfo.library.unt.edu/npr/library/nprrpt/annrpt/redtpe93/index.html 
Grant R, Nijman J (eds.). 1998. The Global Crisis in Foreign Aid; Syracuse University Press: Syracuse, NY, USA.

Haugaard L. 1997. Development aid: some small steps forward. NACLA Report on the Americas 31: 29-33.

Hook SW. 1995. National Interest and Foreign Aid; Lynne Rienner: Boulder, CO, USA.

Justice J. 1989. Policies, Plans, and People: Foreign Aid and Health Development; University of California Press: Berkeley, CA, USA.

Lancaster C. 1999. Aid to Africa: So much to do, so little done; University of Chicago: Chicago.

La Voy D. 1996. Mainstreaming Participation at USAID: Where we are in the Revolution - One Person's Account. Retrieved November 2002, from USAID: http://www.usaid.gov

La Voy D, Charles C. 1998. Engaging Customer Participation: USAID's Organizational Change Experience. Retrieved November 2002, from USAID: http://www.usaid.gov Long CM. 2001. Participation of the Poor in Development Initiatives: Taking Their Rightful Place; Earthscan: London.

OECD (Organisation for Economic Co-operation and Development). 1994. DAC Orientations on Participatory Development and Good Governance; OECD Working Papers. OECD: Paris.

Rondinelli D. 1989. Reforming U.S. foreign aid policy: constraints on development assistance. Policy Studies Journal 18(1): 67-85.

Saltmarshe D, Ireland M, McGregor JA. 2003. The performance framework: a systems approach to understanding performance management. Public Administration and Development 23(5): ?-?.

Taher N. 2001. In the shadow of politics: US AID-government of Egypt relations and urban housing intervention. Environment and Urbanization 13(1): 61-76.

Thompson J. 1998. Participatory Approaches in Government Bureaucracies: Facilitating Institutional Change. In Who Changes? Institutionalizing Participation in Development, Blackburn J (ed.); Intermediate Technology Publications: London; 108-117.

Unom S. 2000. Whose accountability? Participation and partnership in a disabling environment. IDS Bulletin 31(1): 78-87.

USAID. 1994-1997. The Participation Forums, 1-23. Retrieved February 2003, from USAID: http://www.usaid.gov 
USAID. 1996. Toward the New USAID II: Three Years of Reform Progress. Retrieved July 2003 from USAID’s Development Clearinghouse, ID \# PN-ACA-543:

http://www.dec.org

USAID. n.d. The Participatory Practices, 1-11. Retrieved June 2003, from USAID: http://www.usaid.gov

Wilson JQ. 1989. Bureaucracy: What Government Agencies do and why they do it; Basic Books: New York. 